\title{
Impact Analysis of Row Planting Teff Crop Technology on Household Welfare:A Case Study of Smallholder Farmers of Duna District in Hadiya Zone, Ethiopia
}

\author{
Negese Tamirat" \\ Department of Economics, Jimma University, Ethiopia
}

\begin{abstract}
Adoption of product increasing row planting agricultural technologies is a prerequisite for achieving agricultural growth and development, contributing towards improved rural household welfare. However, the link between row planting agricultural technology adoption and household welfare remains poorly understood due to lack of comprehensive measures of household welfare and the exclusive focus on measures such as crop yield and productivity outcomes. This study was designed to assess the adoption and impact of row planting of teff crop on smallholder farmer food consumption expenditure in Duna district using cross sectional survey data gathered in 2018/19 from a sample of 355 teff smallholder famers selected from six kebeles to represent major teff producers. Logit regression and propensity score matching (PSM) techniques were employed for data analysis. The results revealed that adoption of teff row planting technology had a significant positive impact on household welfare measured by higher annual crop yield as well as expenditures on food consumption. Logit regression results reveals that sex of household head, education of household head, family size of household head, holding of livestock, use of credit, extension services access and attending farmers' training center were found to be important factors influencing farmers adoption decisions. The results confirm the role of row planting technology adoption in improving household welfare among smallholder farmers as higher crop yields from adoption translate into reduced poverty.
\end{abstract}

Keywords: Adoption, Teff, Impact, Propensity Score Matching, Row Planting Technology

DOI: $10.7176 / \mathrm{JESD} / 11-5-02$

Publication date:March $31^{\text {st }} 2020$

\section{Introduction}

Row planting agricultural technology is among the most impactful areas of modern agricultural technology, driven by the fundamental need for food and for feeding an ever-growing population. The Row planting agricultural technology and improved agricultural technology practices play a key role in enhancing agricultural production in improving smallholder farmer in developing countries. In Less Developed Countries (LDCs) in general and SubSaharan Africa (SSA) in particular, economic policy highly depended on agriculture. Consequently, growth in the agricultural sector has been critical to achieving poverty reduction and income growth creating spillover effects to the remaining sectors [1]. However, production and productivity of the agricultural sector in SSA and much of the developing world is generally low due to poor technological adoption [2,3\&4]. Agriculture is by far the largest sector of Ethiopia's economy serving as a basis for the country's food security and source of livelihood for over $80 \%$ of its people. The sector in the country's accounts for about $50 \%$ of the Gross Domestic Product (GDP), $90 \%$ of the total export revenue, $85 \%$ employment of the country's labor force and accounts $70 \%$ of raw materials requirement of the country's industries [5]. Consequently, it has been the core element of the country's Agriculture Development Led Industrialization (ADLI) strategy for many years [6].

The principal grain crops grown in Ethiopia are teff, wheat, and barley, which are primarily cool weather crops; and corn, sorghum, and millet, which are warm weather grain crops. Teff is one of the major food staple crops in Ethiopia. It is the largest value in terms of both production and consumption in Ethiopia and the value of the commercial surplus of teff is second only to coffee [7], but national average product levels are low. A number of factors have been cited as responsible for such a low level of average yield. First and for most the nature of the agricultural sector which is characterized by rain fed, subsistence oriented, broadcast farming system, low adoption of row planting technology, poor agricultural performance, income variability and high population growth. Consequently, the country has been unable to meet the high demand for food thereby remaining net importer despite its huge potential for wheat production [8].

Broadcast sowing technique is the most common and widely employed practice among smallholder farmers in Ethiopia. The method employs broadcasting of seed by hand at high speed a practice with potentially negative consequences. In particular, the tradition of broadcasting seeds is likely to lead to a fall in yield due mainly to the difficulty in hoeing and hand weeding; and the competition with weed resulting from the uneven distribution of the seeds. Teff is among the crops commonly cultivated using the traditional broadcast planting possibly explaining the considerably low levels of yield associated with teff production. Consequently, adoption of improved agricultural technologies such as row planting and transplanting, where the seed rate is reduced and more space 
between seedlings is given, have been shown to achieve important yield improvements over traditional broadcasting sowing because these technologies allow for better weeding, diminish competition between seedlings, and allow for better branching out and nutrient uptake of the plants [9\&10].

An empirical study carried out by [11], showed that the significant impact of row planting teff crop on households' income by using two models like the propensity Score Matching (PSM) and Heckman two-stage selection model. The variables like level of education, cultivated land size, tropical livestock unit, access to extension services, availability of family labor and nearness to farmers training center are significant on row planting teff crop and on household income. An empirical study carried out by [12] in their study showed that Effect of Method of Sowing on Yield and Yield Components of teff. According to their studies teff row planting technology had acceptable more teff crop yield and income than the broadcast planting method. A study by [13] in Beressa and Umbrello Watersheds showed that Impact of agricultural technology on farm production. According to [13] adoption of row planting technology were important to agricultural sector growth. According to the study [14], with low educational level and small land holdings are less likely to adopt improved seed and fertilizer technologies, by panel data using probit model in Uganda.

Several row planting technology adoption research findings have pointed to the fact that the use of row planting agricultural technology could lead to significant increase in agricultural production in Ethiopia and stimulate the transition from low production subsistence agriculture to a high production agro-industrial economy. [15] made a study entitled adoption of modern agricultural production technology by farm households in Ghana using logit model as a tool over 300 farmers who found that, plot size, expected returns from technology adoption, access to credit, and extension services are the factors that significantly affect technology adoption decisions of small farm households in the west district area of that country.

\section{Methods}

\subsection{The study area}

The study was conducted in South Nations, Nationalities, People's Region (SNNPR), Hadiya Zone, and Duna Woreda, Ethiopia. The Woreda is geographically located $7^{\circ} 37^{\prime} 19^{\prime \prime} \mathrm{N}$ latitude and $37^{\circ} 37^{\prime} 14^{\prime \prime}$ E longitudes. In this study, both primary and secondary data sources were used. Discussion with group of farmers and agricultural extension staff was done to generate information. Key informants were also used as information source from different actors. A multi stage sampling procedure was used to select the kebeles and sample households. In the first stage, 6 kebeles were selected purposively from 17 teff producing kebeles based on their agro ecological zone. In the second stage after lists of farmers were obtained from the district Agricultural and rural development office, farmers who were cultivating teff in six kebeles, 155 adopter sample household heads were taken as respondent using probability proportional to size. 200 non-adopter respondents were selected using simple random sampling method based on their proportion. The data was collected from December 2018 up to April 2018 for five months. In this study, descriptive statistics (percentage, frequency and mean) were mainly used. The descriptive analysis was conducted using Statistical Package for Social Science (SPPS). Given our dependent variable is dichotomous; the probit and logit models are commonly used models to estimate the model specification. In this study, the logit model is employed for its simplicity and ease of interpretation of the parameter estimates in probability terms.

$$
R P T_{i}=\alpha+\beta X_{i}+u_{i}
$$

Where $R P T_{i}$ is the adoption status of household $i$, which takes score 1 for households who have adopted row planting technology in teff production and 0 otherwise.; $X_{i}$ is vector of covariates including socioeconomic, demographic and institutional factors that are presumed to affect adoption status of household $i ; u_{i}$ is the error term of the model such that $u_{i} \sim N\left(0, \sigma^{2}\right)$; and $\alpha, \beta$ are model parameters to be estimated. The main interest of our analysis to evaluate the impact of adoption of row planting technology on household welfare by employing the three welfare outcome indicators at household level: teff crop yield, measured by the total amount of teff crop production at the household level expressed in quintals/ha of land; total annual household income (expressed in ETB) and per capita household food consumption expenditure, calculated as the ratio of total household food consumption expenditure to total family size expressed in birr (ETB). To assess whether adoption status is associated with differences in household level welfare outcomes, the following regression specification may be employed.

$$
Y_{i}=\alpha+\gamma R P T_{i}+\boldsymbol{\beta} X_{i}+\xi_{i}
$$

Where $Y$ is a measure of household welfare; $\gamma$ is the parameter of interest for estimating the effect of adoption; $\xi$ is the model error term. A major methodological challenge associated with the estimation of model (2) through the usual least-square procedure is that the parameter $\gamma$ would typically be biased a situation commonly referred to as 'self-selection' bias [16]. This is mainly because households' decision to adopt the planting technique is likely not random and that such decisions could be systematically related to other factors that affect household welfare outcomes. Besides, there are also unobservable differences between the two groups of households. The implication is that the two groups are not comparable, and that any difference between the two in terms of welfare cannot be attributed to differences in adoption status alone. Consequently, measurement of impact based on $\gamma$ fails to 
separate the effect of adoption from that attributable to systematic differences.

\section{Results and Discussion}

\subsection{Description of Teff Planting Methods}

The number of sample farmers who practiced planting teff in a row was $45.32 \%$ while those who used the conventional planting method comprise $54.68 \%$ of sample farmers from the total randomly selected 355 sample farmers.

Table 1: Sample farm households by adoption status of teff planting method

\begin{tabular}{lcc}
\hline \hline Planting method & Frequency & Percent \\
\hline Non-adopters & 200 & 54.68 \\
Adopters & 155 & 45.32 \\
Total & 355 & 100 \\
\hline \hline
\end{tabular}

Source: own computation based on data (2018)

As regard to the age of household heads, average age of the sample household head was found to be 56.422 years where the minimum is 28 and the maximum is 81 . The average sample household age of adopters of row planting is 53 and the corresponding figure for non-adopters of row planting is 57 . The mean age difference between adopters and non-adopters of row planting is 4 . The mean and stander deviation of household education were 2.149 and .878 respectively. According to education level of the household heads majority sample household heads are literate. Regard to the family size of sample household heads family size ranges between 3 and 9 . Average family size is 5.419 people per household heads. Average family size of household heads between adopters and non-adopters of row planting teff technology were 5.10 and 4.00, and difference between adopters and non-adopters of row planting of teff technology is 1.10. As regard to the landholding of the sample household heads varies from .125 ha to 3 ha with an average figure of 1.784 ha. The average livestock holding in Tropical Livestock Unit for the sample households (including cattle, horse, donkey, mule, sheep and goats, and chicken) was 7.798 TLU with the minimum and the maximum holdings of 7 TLU and 17.8 TLU respectively. Average livestock holding in Tropical Livestock Unit for adopters and non - adopters were 11.02 TLU and 8.32 TLU respectively.

Table 2: Summarized list of variable

\begin{tabular}{|c|c|c|c|c|c|}
\hline Variable & Obs & Mean & Std. Dev. & Min & Max \\
\hline Rpth & 355 & $\begin{array}{c}.473 \\
\end{array}$ & (.499 & 0 & 1 \\
\hline Sexh & 355 & .653 & .476 & 0 & 1 \\
\hline Ageh & 355 & 56.422 & 13.375 & 28 & 81 \\
\hline Edu & 355 & 2.149 & .878 & 1 & 4 \\
\hline Clsize & 355 & 1.784 & .854 & .125 & 3 \\
\hline Fsize & 355 & 5.419 & 1.367 & 3 & 9 \\
\hline Tlu & 355 & 7.798 & 4.274 & 7 & 17.8 \\
\hline Usecrids & 355 & .588 & .492 & 0 & 1 \\
\hline Rai & 355 & .532 & .499 & 0 & 1 \\
\hline Afl & 355 & .616 & .486 & 0 & 1 \\
\hline Atc & 355 & .578 & .434 & 0 & 1 \\
\hline
\end{tabular}

Source: own computation based on data (2018)

\subsection{Econometric results}

Model estimates for the determinants of household decisions to adopt the row planting technology are presented in Table 3. The goodness fit with regard to the predictive efficiency was high with $301(85 \%)$ of the 355 sample household included in the model correctly predicted. 
Table 3: Estimates of the determinants of households' adoption decisions $(n=355)$

\begin{tabular}{|c|c|c|c|c|}
\hline Variable & $\begin{array}{c}\text { Robust } \\
\text { Coefficient }\end{array}$ & Odds Ratio & $\mathrm{P}>|\mathrm{z}|$ & $(d y / d x$ \\
\hline AGEHH & -0.002 & 0.989 & 0.698 & -0.032 \\
\hline SEHH & $1.106 * * *$ & 3.051 & 0.003 & 0.227 \\
\hline FSIZE & $0.324 * *$ & 1.383 & 0.020 & 0.080 \\
\hline EDU & $0.130 * *$ & 1.140 & 0.033 & 0.030 \\
\hline CLSIZE & 3.563 & 35.288 & 0.305 & 0.886 \\
\hline TLU & $0.046^{*}$ & 1.047 & 0.058 & 0.011 \\
\hline CRUHH & $0.690 *$ & 1.994 & 0.087 & 0.170 \\
\hline RAI & 0.542 & 1.720 & 0.163 & 0.127 \\
\hline AFL & 0.173 & 1.189 & 0.703 & 0.040 \\
\hline EXTEN & $1.046 * * *$ & 2.847 & 0.003 & 0.236 \\
\hline FTC & $0.772 * * *$ & 2.174 & 0.006 & 0.181 \\
\hline Cons & -5.061 & 0.0064 & $0.000 * * *$ & \\
\hline
\end{tabular}

Source: Computed from own survey data (2018). $\quad{ }^{* * *} \mathrm{P}<0.01,{ }^{* *} \mathrm{P}<0.05$ and $* \mathrm{P}<0.10$.

Accordingly, seven of the eleven variables included (sex of household head, education of household head, family size of household head, holding of livestock, use of credit, extension services access and attending farmers' training center) were found to have significant association with the probability of practicing row planting technology. On the other hand, factors such as sex of household head, education of household head, family size of household head, holding of livestock, use of credit, extension services access and attending farmers' training center had all significant positive associations with households' adoption decisions, with marginal effects ranging between $1.1 \%$ to $22.7 \%$ on average (cetris paribus). More specifically, sex of household headed, family size, credit service, extension service, farmers training centers and livestock possession in TLU were respectively associated with a $22.7 \%, 8 \%, 17 \%, 23.6 \%, 18.1 \%$ and $1.1 \%$ higher probabilities of adoption on average, all else remaining the same. Moreover, households with access to credit, access to extension services and farmers training centers respectively found to be $17 \%, 23.6 \%$ and $18.1 \%$ more likely to adopt row planting teff crop technology respectively compared to those without access to these services. The results from the econometric analysis were qualitatively similar to those of the descriptive statistics results.

PSM algorithm can be selected based on its own criteria: balancing test, Pseudo R-square (low), matched sample size (large) and LR chi-square (insignificant), the algorithm which are selected from four matching algorithms: nearest neighbor matching (NNM), radius matching (RM), caliper matching, and kernel matching (KM). Accordingly, a nearest neighbor matching method with of 3 was found to be the best estimator. Accordingly, nearest neighbor matching method 3 was found to be the best estimator, since it resulted in the least pseudo Rsquare $(0.017)$, had insignificant LR chi-square $(L R=3.52, p=0.875)$ and large matched sample size $(331)$ by discarding 4 unmatched farmers from the total of 355 households. Table 4 reports the estimated treatment effects from the propensity score matching. Results revealed that row planting technology had significant effect on household welfare as evidenced by the significantly higher per capita consumption expenditure and annual income resulting from adoption $(\mathrm{p}<0.01)$.

Table 4: The Average Treatment Effect on the Treated

\begin{tabular}{clllll}
\hline Outcome & Treated & Controls & Difference & BSE & T-stat \\
\hline Teff yield (Qt/ha (year)) & 14.45 & 8.25 & 6.20 & 0.78 & $3.46^{* * *}$ \\
Income per capita & $17,856.08$ & $8,687.53$ & $9,168.55$ & $1,085.26$ & $5.50^{* * * *}$ \\
Food Consumption per capita & $15,458.23$ & $8,898.48$ & $6,559.75$ & $1,385.78$ & $3.50^{* * *}$
\end{tabular}

Source: Computed from own survey data (2018). ${ }^{* * *} \mathrm{P}<0.01$

Specifically, the food consumption expenditure of adopting farmers was much higher than those who didn't adopt on average by 6,559.75Birr. Given the mean level of consumption per capita in the study area, which is hardly in excess of half the average treatment effect reported implying that the estimated effect associated with adoption is quite large. Similarly, the income of adopters was also found to be significantly higher than those of their non-adopter counterparts by 9,168.55Birr on overage. Compared to the mean annual income in the area reported to be 12982.45 the estimated effect is quite substantial as it translates in to nearly a $70 \%$ of increment in the annual incomes in the study area. On the other hand, the results also show that row planting technology had significant effect on teff yield at $1 \%$ significance level $(\mathrm{p}<0.01)$ during the $2017 / 18$ cropping season. The average yields of teff crop of adopter households were higher by 6.20 quintals/ha when compared with the average yields of non-adopter households. This is quite a substantial yield improvement considering the mean teff yield in the study area. These findings indicate that adoption of row planting technique had in deed a significant positive impact on households' welfare. In particular, adoption was associated with significantly higher consumption expenditure per capita, increased net annual income, higher crop yield and increased spending on farm inputs. Hence, adoption 
of row planting of teff had a positive impact on the life of the adopters indicating positive welfare effect or reduction of poverty level on the side of the adopters.

\section{Conclusion and Policy Implications}

In this study, we assessed the adoption of row planting of teff technology and its impact on household welfare among teff farmers in Duna district, Ethiopia. Both descriptive and econometrics methods were employed for data analysis. In particular, propensity score matching approach was used to compare adopter households with nonadopters in terms of three key measure of household wellbeing; yields, household food consumption expenditure, and annual income. The matching techniques employed were the nearest neighborhoods matching, radius matching, caliper matching, and kernel matching. Among the algorithms used nearest neighbor matching (3) was found to be the best estimator of data based on balancing test, pseudo $\mathrm{R}^{2}$ and sample size. The results showed that row planting of teff technology had significantly positive impact on farmers' yields, food consumption expenditure and income. Moreover, key household characteristics such as the sex of household head, education of household head, family size of household head, holding of livestock, use of credit, extension services access and attending farmers' training center were found to be important factors underlying households' adoption decisions. The sensitivity analysis also showed that the estimates are almost free from unobserved covariates. Consequently, it can be concluded that the overall the results are remarkably robust and the analysis supports the robustness of the matching estimates. Therefore, it is used to scaling up the best teff row planting technology and practices of the adopters to other farmers can be considered as one option to enhance teff crop yields, household income and household food consumption expenditure in the study area while introducing new agricultural practices and technologies is another option.

Understanding the factors that hinder adoption of agricultural technology is essential in planning and executing technology related programs for meeting the challenges of teff production in our country. Therefore, to enhance row planting of teff adoption by farmers, it's important for policy makers and planners of new technology to understand farmers need as well as their ability to adopt technology in order to come up with technology that will suit them. It is better to encourage row planting technology adoption because the results of this study signified that application of row planting of teff increase substantially both the productivity and income of adopters. The females should go in hand to hand with males to improve productivity and income of household. Ethiopia Federal Government said that without female participation, we cannot bring sustainable development and growth. However, in study area female households headed were less likely to participate in row planting teff crop technology as compare to male households headed. To reduce this problem, the local government should create the necessary awareness among the females rather than male still participation ratio become equal, relatively. The fact that, female household headed in Ethiopia lack the necessary means to get extension advices because they expended more time on non-marketable homework and not attended administrative meeting in their own area.

Improved teff production technology involves the use of different practices, which require knowledge, and skill of application and management. Education was found to have a strong relation with the adoption of row planting of teff production technology as it enhances teff crop yields. Therefore, due emphasis has to be given towards strengthening rural farmer's education at different levels for small farm households using farmers training centers. Increasing the number of cooperatives organization in the rural area in which the farmers will be able to get credit are basis in enhancing the adoption of row planting teff technology. Further, it is apparent from the study that if farmers get credit more easily, they would use row planting technology to enhance teff crop yields. Thus, the credit facility should target poor farmers especially those who were not adopting the row planting technology due to lack of operating capital. This may encourage the farmers to do commercial farming practice in which they can build their asset to implement the adoption of row planting of teff technology on their farms. The agricultural research and extension activities need to consider additional agronomic practices along with the row planting method in order to increase teff production, and for the successful promotion, adoption and scaling up of good agronomic practices and extension should contact farmers individually as well as in group to be awarded in terms of row planting of teff is suitable to improve household production. In order to attain food security of the nation policy makers should devise more effective farmers' training mechanisms and provide more applicable teff production mechanizations effective on the process of teff production. The introduction of the above measures into the picture of technology adoption, therefore, could enhance the number of adopters and the cropped area under row planting technology. Hence, expansion in the level of technology adoption would consequently result in substantial teff productivity and income on a sustainable basis.

\section{Reference}

1. World Bank (2014). Ethiopia poverty Assessment. Document of the WB for official use only.

2. Abraham B, Araya H, Berhe T, Edwards S, Gujja B, Khadka R, Sen D, Koma Y, Sharif A, and Styger E. (2014). The system of crop intensification: Reports from the field on Improving agricultural production, food security, and resilience to climate change for multiple crops. Addis Ababa, Ethiopia. 
3. Gashaw T, Alan B, Nicholas M, and Tanguy B. (2014). The impact of the use of new technologies on farmers wheat yield in Ethiopia. International Food Policy Research Institute (IFPRI). Washington.

4. Lulit M, Ermias E, and Zelalem H, (2012). Public investment in irrigation and training for agriculture-Led development: a CGE approach for Ethiopia. Addis Ababa, Ethiopia.

5. MoFED. (2012). Ethiopian's progress towards eradicating poverty: An interim report on poverty analysis Study. Addis Ababa, Ethiopia.

6. ATA. (2013). Results of 2012 New Tef Technologies Demonstration Trials Draft Report VF. Addis Ababa, Ethiopia. 34p.

7. Minten, B., S. Tamru, E. Engida, and T. Kuma. ( 2013 ). Ethiopia's Value Chains on the Move: The Case of Teff. ESSP II Working Paper 52. International Food Policy Research Institute (IFPRI). Addis Ababa, Ethiopia.

8. Rashid, S. (2010). Staple food prices in Ethiopia. Maputo, Mozambique.

9. Astatke, A.M., Jabbar, M.A., Mohamed, Salem and T. Erkossa. (2002). Technical and Economic Performance of Animal-drawn Implements for Minimum Tillage: Experience on Vertisols in Ethiopia, 38(2).

10. Chauhan, H.S, S.K.A, Anuruddhika, S.W., Manoja, D.K., Sakinda, and B.W. Upali. (2014). Effect of rice establishment methods on weedy rice infestation and grain yield of cultivated rice (O. Sativa L.) In Sri Lanka Crop Prot.55.

11. Yonas, B. (2013). The impact of row planting of teff crop on rural Household income: A case of Tahtay Maychew wereda, Tigrai, Ethiopia.

12. Bekalu, Abebe and Tenaw, Workayehu. (2015). Effect of Method of Sowing on Yield and Yield Components of Tef. Global Journal of Chemistry, 2(1):, 2454-2490.

13. Debela. (2011). The impact of agricultural technology on farm production: the case of Beressa and Umbrello Watersheds.

14. Ibrahim, K. (2013). Constraints to agricultural technology adoption in Uganda: Evidence from the 2005 / $06-$ 2009/10 Uganda National Panel Survey.

15. Mamudu AA, Emelia G, and Samuel KD. (2012). Adoption of modern agricultural production technologies by farm households in Ghana: What factors influence their decisions? J. Biol. Agric. Healthcare 2(3).

16. Wooldridge, J. M. (2013). Introductory econometrics: A modern approach. Mason, OH: South-Western Cengage Learning. 